\title{
Middle atmosphere response to different descriptions of the 11-yr solar cycle in spectral irradiance in a chemistry-climate model
}

\author{
W. H. Swartz ${ }^{1}$, R. S. Stolarski ${ }^{2,3}$, L. D. Oman ${ }^{3}$, E. L. Fleming ${ }^{3,4}$, and C. H. Jackman ${ }^{3}$ \\ ${ }^{1}$ Johns Hopkins University Applied Physics Laboratory, Laurel, MD, USA \\ ${ }^{2}$ Department of Earth and Planetary Sciences, Johns Hopkins University, Baltimore, MD, USA \\ ${ }^{3}$ NASA Goddard Space Flight Center, Greenbelt, MD, USA \\ ${ }^{4}$ Science Systems and Applications, Inc., Lanham, MD, USA \\ Correspondence to: W. H. Swartz (bill.swartz@jhuapl.edu)
}

Received: 21 January 2012 - Published in Atmos. Chem. Phys. Discuss.: 8 March 2012

Revised: 14 June 2012 - Accepted: 15 June 2012 - Published: 12 July 2012

\begin{abstract}
The 11-yr solar cycle in solar spectral irradiance (SSI) inferred from measurements by the SOlar Radiation \& Climate Experiment (SORCE) suggests a much larger variation in the ultraviolet than previously accepted. We present middle atmosphere ozone and temperature responses to the solar cycles in SORCE SSI and the ubiquitous Naval Research Laboratory (NRL) SSI reconstruction using the Goddard Earth Observing System chemistry-climate model (GEOSCCM). The results are largely consistent with other recent modeling studies. The modeled ozone response is positive throughout the stratosphere and lower mesosphere using the NRL SSI, while the SORCE SSI produces a response that is larger in the lower stratosphere but out of phase with respect to total solar irradiance above $45 \mathrm{~km}$. The modeled responses in total ozone are similar to those derived from satellite and ground-based measurements, 36 Dobson Units per 100 units of $10.7-\mathrm{cm}$ radio flux $\left(F_{10.7}\right)$ in the tropics. The peak zonal mean tropical temperature response using the SORCE SSI is nearly $2 \mathrm{~K}$ per 100 units $F_{10.7}-3$ times larger than the simulation using the NRL SSI. The GEOSCCM and the Goddard Space Flight Center (GSFC) 2-D coupled model are used to examine how the SSI solar cycle affects the atmosphere through direct solar heating and photolysis processes individually. Middle atmosphere ozone is affected almost entirely through photolysis, whereas the solar cycle in temperature is caused both through direct heating and photolysis feedbacks, processes that are mostly linearly separable. This is important in that it means that chemistry-transport models should simulate the solar cycle in ozone well, while general circulation models
\end{abstract}

without coupled chemistry will underestimate the temperature response to the solar cycle significantly in the middle atmosphere. Further, the net ozone response results from the balance of ozone production at wavelengths less than $242 \mathrm{~nm}$ and destruction at longer wavelengths, coincidentally corresponding to the wavelength regimes of the SOLar STellar Irradiance Comparison Experiment (SOLSTICE) and Spectral Irradiance Monitor (SIM) on SORCE, respectively. A higher wavelength-resolution analysis of the spectral response could allow for a better prediction of the atmospheric response to arbitrary SSI variations.

\section{Introduction}

Recent measurements of the solar spectral irradiance (SSI) made by the the SOlar Radiation \& Climate Experiment (SORCE) mission (Rottman, 2005) have brought into question long-held views of how the SSI varies as a function of the 11-yr solar cycle. Based on SORCE observations during the latter part of the declining phase of solar cycle 23 (20042007), Harder et al. (2009) suggested that the magnitude of the solar cycle variation in the ultraviolet (UV), from 200 to $400 \mathrm{~nm}$, is several times larger than previously thought. Further, they posited that the SORCE SSI variation in the visible and near-infrared (NIR) is out of phase with the UV and total solar irradiance (TSI) (i.e., the visible and NIR flux actually increased approaching the last solar minimum). The larger UV variation has significant implications for the response of

Published by Copernicus Publications on behalf of the European Geosciences Union. 
the stratosphere and mesosphere and potentially climate to the solar cycle.

Several studies (Cahalan et al., 2010; Haigh et al., 2010; Merkel et al., 2011; Ineson et al., 2011) suggest that atmospheric models forced with the SORCE SSI lead to better agreement with the solar cycle response inferred from observations than simulations based on the widely accepted Naval Research Laboratory (NRL) SSI reconstruction derived from long-term solar observations (Lean, 2000), implying that the solar cycle in SSI derived from SORCE data is more consistent with observations. Garcia (2010) and Matthes (2011), however, have noted caveats with both the completeness of the model calculations and the short data records used. In addition, Morrill et al. (2012), DeLand and Cebula (2012), and Lean and DeLand (2012) have more directly examined the SSI measurements themselves in comparison to other coincident and historical observations. Although the SORCE SSI measurements have been found to be internally consistent and agree with other observations on short time scales (e.g., 27-day solar rotation), these studies question the veracity of the 11-yr solar cycle-derived trends.

In this paper we present results of simulations made with two state-of-the-art chemistry-climate models (CCMs), the Goddard Earth Observing System (GEOS) 3-D CCM and the Goddard Space Flight Center (GSFC) 2-D model, using both the NRL and SORCE SSI. We examine the individual mechanisms of atmospheric response to solar cycle variations in SSI through direct solar heating and photolysis. We also explore how middle atmosphere ozone responds to solar cycle variations in different parts of the SSI spectrum and what implications can be drawn regarding the inferred SORCE solar cycle in SSI.

\section{Background}

Temporal variations in the solar energy reaching the Earth change the energy input that forces atmospheric composition and temperature and the Earth's climate (for a recent review, see Gray et al., 2010). The spectral distribution of solar irradiance is vital for determining the Earth's response to solar cycle variations (Zhong et al., 2008). Although the 11-yr solar cycle relative variation in TSI is only $0.1 \%$, the solar variation of the SSI, as a function of wavelength, can be much larger - greater than $10 \%$ in the oxygen Schumann-Runge bands, for example. The absolute magnitude of the solar radiation in the UV is much smaller than that at longer wavelengths, but its absorption in the middle atmosphere is critical to maintaining the composition, thermal structure, and dynamics of the atmosphere.

With the advent of space-based observations, beginning in 1978 , the variability of the solar irradiance on minute-todecadal timescales has been measured (Fröhlich and Lean, 2004). The traditional view of the 11-yr solar cycle holds that the UV, visible, and IR portions of the SSI rise and fall in phase with the TSI and other solar proxies, such as the solar 10.7-cm radio flux, $F_{10.7}$ (Lean, 2000). This view is based on both observations and our understanding of solar physics. How changes in the solar energy reaching the Earth impact climate (temperature and precipitation) variability has been the focus of intense investigation (e.g., Haigh, 1996; Shindell et al., 1999, 2001; Rind, 2002; Rind et al., 2004, 2008; Ineson et al., 2011).

Accurate characterization of the SSI is so important that not one but two separate instruments measuring UV SSI were flown on the Upper Atmosphere Research Satellite (UARS): the SOLar STellar Irradiance Comparison Experiment (SOLSTICE) (Rottman et al., 1993) and the Solar Ultraviolet Spectral Irradiance Monitor (SUSIM) (Brueckner et al., 1993). Recent satellite measurements by SORCE, however, challenge the canonical view of SSI solar cycle variability represented by the work of Lean (2000). Since it was launched in 2003, the SORCE mission has been measuring SSI and TSI (Rottman et al., 2005; McClintock et al., 2005; Kopp et al., 2005; Kopp and Lean, 2011).

Solar UV radiation has two primary direct effects on the atmosphere: atmospheric heating and the photolysis of molecular oxygen $\left(\mathrm{O}_{2}\right)$ and trace gases, such as ozone (e.g., Brasseur and Solomon, 1986). In the stratosphere and mesosphere, solar heating is principally through absorption of UV radiation by ozone in the Hartley $(200-300 \mathrm{~nm})$ and Huggins $(300-360 \mathrm{~nm})$ bands, with absorption of visible light by ozone becoming more important in the lower stratosphere. Absorption by the $\mathrm{O}_{2}$ Schumann-Runge system $(<205 \mathrm{~nm})$ is important in the upper mesosphere, but heating via the Herzberg continuum (190-242 nm) has only a second-order effect in the middle atmosphere. Absorption of visible and near-infrared radiation in the lower atmosphere by ozone, $\mathrm{H}_{2} \mathrm{O}, \mathrm{CO}_{2}, \mathrm{NO}_{2}$, and other minor gases contributes to heating in this region. Through photolysis, solar radiation is the driver of atmospheric chemistry; in the stratosphere, solar radiation is directly responsible for the ozone production and loss processes that together control the amount of ultraviolet radiation reaching the lower atmosphere and surface.

Precisely how ozone and temperature respond to solar cycle variability depends on the spectral dependence of SSI variation and the interplay between atmospheric heating and photolysis. Direct heating increases during the ascending phase of the solar cycle, increasing atmospheric temperature and decreasing ozone concentrations, due to faster temperature-dependent ozone loss reactions, which consequently cause a negative feedback on temperature as the primary absorber of radiation is destroyed. Increased solar radiation also increases ozone production (through $\mathrm{O}_{2}$ photolysis) and loss (through increased atomic oxygen concentrations resulting from greater ozone photolysis). Net ozone production leads to more absorption and heating. The balance of these interrelated and competing processes and their wavelength dependencies can be explored using models. 
Typical atmospheric general circulation models (GCMs) include the solar direct atmospheric heating term and have interactive radiation and dynamics, but chemistry (including photochemistry) is specified and does not include solar modulation of chemistry or chemistry feedbacks through changes in composition. Chemistry-transport models (CTMs) include changes in photochemistry, but the radiation and dynamics are specified and non-interactive with the chemistry. What is therefore needed to address the effects of changing solar irradiance on both heating and photolysis is a chemistry-climate model, which treats both effects self-consistently, with interactive chemistry, radiation, and dynamics.

Several modeling studies have examined the impact of the solar cycle on the middle atmosphere, using 2-D models (e.g., Garcia et al., 1984; Fleming et al., 1995; Huang and Brasseur, 1993; Haigh et al., 2010), 3-D CTMs (e.g., Stolarski et al., 2006), and 3-D CCMs (e.g., Marsh et al., 2007; Austin et al., 2008). These previous modeling studies have been based at least in part on the NRL reconstruction of SSI and have found temperature and ozone responses to the 11-yr solar cycle that, although different from measurementderived responses in certain details, are largely consistent with long-term observations (e.g., Austin et al., 2008). The ozone response, for example, has been found to be in-phase with TSI in the stratosphere and lower mesosphere.

More recently, studies have looked at the SORCE SSI specifically. Cahalan et al. (2010) investigated the impact of the new SORCE SSI in the Goddard Institute for Space Studies (GISS) modelE GCM in comparison to the NRL reconstruction of SSI and found that the SORCE SSI led to stratospheric heating that agreed better with the solar cycle impact on temperature inferred from Halogen Occultation Experiment (HALOE) measurements (Remsberg, 2008). Haigh et al. (2010) modeled both the NRL and SORCE SSI in a 2-D model and predicted ozone variations in phase with the solar cycle below $45 \mathrm{~km}$ and out of phase above when using the SORCE SSI. They also included observational evidence to support the SORCE SSI fingerprint in stratospheric ozone using Aura/Microwave Limb Sounder (MLS) observations. The period of available SORCE data and the model comparison of Haigh et al. with MLS covered only part of a solar cycle, however, making it very difficult to draw statistically robust conclusions (Garcia, 2010). And although both studies led to conclusions supporting the SORCE SSI, they predicted opposite surface temperature responses, with Cahalan et al. in phase with TSI and Haigh et al. out of phase with TSI. Merkel et al. (2011) performed simulations using the Whole Atmosphere Community Climate Model (WACCM), predicting an ozone response similar to Haigh et al. when using SORCE SSI, out-of-phase with the solar cycle above approximately $40 \mathrm{~km}$. They performed a regression analysis of Thermosphere Ionosphere Mesosphere Energetics and Dynamics (TIMED)/Sounding of the Atmosphere using Broadband Emission Radiometry (SABER) ozone data, a record somewhat longer $(8 \mathrm{yr})$ than the MLS time series analyzed by Haigh et al., and also inferred an out-of-phase response in the lower mesosphere.

How the atmosphere responds to solar cycle variations in the spectral distribution of SSI has important implications for the projection of atmospheric composition and climate on decadal and longer timescales, and even independent of the current debate regarding the magnitude and sign of the solar cycle in SSI, a better understanding of the atmospheric response to changes in SSI is needed.

\section{Solar spectral irradiance}

\subsection{NRL SSI}

Realistic simulations of the solar-forced climate on multidecadal timescales rely on long-term solar irradiance reconstructions. The NRL SSI reconstruction used in this work (Lean, 2000) was derived using a parameterization of the observed temporal variation of SSI over the past $30 \mathrm{yr}$ with proxy indicators needed to represent the known wavelength sources of variability in SSI. Historical records of these proxies were then used to infer SSI variations before satellite observations were available. The model of total solar irradiance variations used was described by Fröhlich and Lean (2004). The specific parameterizations used were those of Fröhlich and Lean (1998) and Lean (2000), which used the Physikalisch-Meteorologisches Observatorium Davos (PMOD) multi-satellite composite. This self-consistent reconstruction of TSI and SSI includes both annual and monthly total solar irradiance and spectral solar irradiance from near hydrogen Lyman- $\alpha(120 \mathrm{~nm})$ through $100 \mu \mathrm{m}$, from January 1882 through December 2008, comprising 12 solar cycles. The irradiance values have been scaled for the present analysis by 0.9965 to match the SORCE/Total Irradiance Monitor (TIM) absolute scale, which has been verified by the Laboratory for Atmospheric and Space Physics (LASP) by comparison with ground-based TSI witness units with a NIST-traceable cryogenic radiometer (see also Kopp and Lean, 2011). Note that the NRL SSI reconstruction is widely used in climate simulations, including those in the IPCC reports (e.g., IPCC, 2007).

\subsection{SORCE SSI}

The SORCE mission comprises the SOLar STellar Irradiance Comparison Experiment (SOLSTICE), the Spectral Irradiance Monitor (SIM), TIM, and the XUV Photometer System (XPS) (Rottman, 2005). Publicly available SOLSTICE data (v. 10), at wavelengths shorter than $310 \mathrm{~nm}$, were used in this work. SIM measures SSI from 200 to $2270 \mathrm{~nm}$, although only data at wavelengths longer than $310 \mathrm{~nm}$ are currently publicly available (see http://lasp.colorado.edu/sorce/ data/data_product_summary.htm). The SORCE team, however, provided us with SIM spectral time series data from 200 to $1600 \mathrm{~nm}$ (J. W. Harder, personal communication, 2010) 


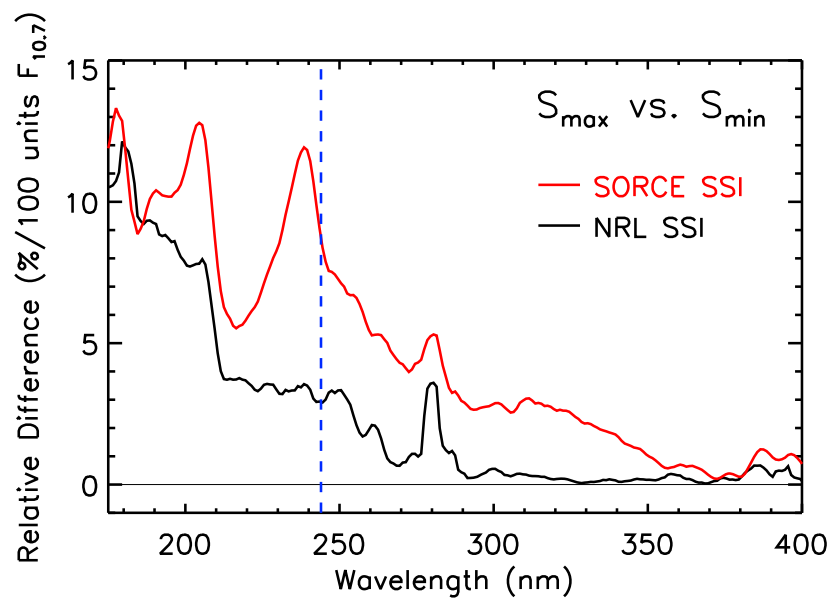

Fig. 1. SSI spectral differences, $S_{\max }$ relative to $S_{\min }$ per 100 units of $F_{10.7}$, derived from NRL and SORCE SSI time series. The vertical dashed line at $244 \mathrm{~nm}$ represents both the wavelength cutoff separating the SORCE SOLSTICE and SIM spectra used and the $\mathrm{O}_{2}$ photolysis threshold $\left(\mathrm{O}_{2}\right.$ photolysis occurs at wavelengths shorter than $242 \mathrm{~nm}$ ).

along with analysis procedures to remove data spikes resulting from spacecraft roll maneuvers. Following the recommendation of the SORCE team, SOLSTICE data were used at wavelengths less than $244 \mathrm{~nm}$, as the signal-to-noise ratio of the SIM measurements is poor in this wavelength region. SORCE data are available starting in April 2004, in the middle of the declining phase of solar cycle 23, extending through the most recent solar minimum, near the end of 2008 , and to present.

\subsection{Derivation of solar maximum/minimum cases}

All the model simulations presented in this paper were performed in time-slice or non-time-dependent mode, stationary in time with respect to solar forcing. Therefore we considered two pairs of SSI spectra representative of solar maximum $\left(S_{\max }\right)$ and minimum $\left(S_{\min }\right)$ conditions, derived from the NRL and SORCE SSI datasets. The spectral differences are shown in Fig. 1.

For the NRL SSI cases, we chose monthly mean spectra from the reconstruction representative of $S_{\max }$ (August 2001) and $S_{\min }$ (June 2007) conditions. These two particular months were selected because they were close to solar max/min conditions, lie on a linear fit correlating the NRL SSI in the ultraviolet and $F_{10.7}$, and are separated by nearly 100 units of $F_{10.7}$. This allows the results to be interpolated or extrapolated approximately to other solar activity conditions, as the effects scale linearly over this range of magnitudes (not shown).

Because SORCE SSI measurements cover only a part of the spectral range simulated in the models used in this work, the following procedure was used to develop $S_{\max }$ (SORCE) and $S_{\min }$ (SORCE) SSI spectra. As mentioned above, SOLSTICE data were used at wavelengths below $244 \mathrm{~nm}$ and SIM was used from 244 to $1600 \mathrm{~nm}$ (SIM actually measures the SSI to roughly $2270 \mathrm{~nm}$, but the inferred solar cycle is considered to be more reliable below $1600 \mathrm{~nm}$ ). At longer wavelengths, the spectra were supplemented with the NRL SSI, but middle atmosphere ozone and temperature are insensitive to these longer wavelengths. This composite SSI time series was correlated with $F_{10.7}$ from September 2004 through November 2007 on a per-wavelength basis, $f_{\lambda}\left(F_{10.7}\right) . S_{\min }(\mathrm{SORCE})$ conditions were then constructed from the fit(s) at solar minimum conditions (November 2007); $S_{\max }$ (SORCE) SSI was inferred for solar conditions of 100 units $F_{10.7}$ greater as $f_{\lambda}\left(F_{10.7}\left(S_{\min }+100\right)\right)$. This linear fitting approach allowed us to infer solar maximum conditions based on the available SORCE time series.

\section{Chemistry-climate models}

\subsection{GEOSCCM}

The 3-D model used in this study was the Goddard Earth Observing System chemistry-climate model (GEOSCCM; Pawson et al., 2008, and references therein). The CCM uses the GEOS-5 atmospheric general circulation model (Rienecker et al., 2008), version 5.2.0, coupled with the StratChem chemical solver developed as a part of the GSFC 3-D CTM (Douglass et al., 1996; Pawson et al., 2008). Eyring et al. (2006) showed that GEOSCCM simulations agree well with observations, both in terms of dynamics/transport and chemistry, and that the evaluated quantities lie well within the range of results obtained by all the models in the study (see also Austin et al., 2008).

The GEOSCCM traditionally uses a fixed input solar spectrum, representative of mean solar cycle conditions, and has in fact been used as a no-solar cycle reference model in past CCM intercomparisons (Austin et al., 2008). For this work, it was therefore necessary to implement the solar cycle in the model. In the GEOSCCM, the solar forcing of atmospheric heating and photolysis are treated separately. This structural aspect of the model code was beneficial for the present study, as we wanted to examine solar cycle effects on heating and photolysis independently.

Six time-slice simulations were performed using the GEOSCCM forced with the NRL SSI reconstruction and solar cycle flux conditions listed in Table 1 (first six table entries) in order to evaluate the independent and combined effects of SSI variations through photolysis and direct atmospheric heating. We replaced the default solar spectrum with $S_{\max }$ and $S_{\min }$ conditions from the NRL SSI. Two additional time-slice simulations were performed based on the SSI measured by SORCE. Compared to transient simulations (with time-dependent solar forcing), time-slice simulations may not fully account for varying tropospheric and ocean 
Table 1. List of CCM time-slice simulations performed with the GEOSCCM and GSFC 2-D model.

\begin{tabular}{llccl}
\hline Designation & Model & SSI Source & Solar Conditions & Solar Cycle in \\
\hline$S_{\max } \mathrm{H}$ & GEOSCCM & NRL & Max & Heating \\
$S_{\min } \mathrm{H}$ & GEOSCCM & NRL & Min & Heating \\
$S_{\max } \mathrm{P}$ & GEOSCCM & NRL & Max & Photolysis \\
$S_{\min } \mathrm{P}$ & GEOSCCM & NRL & Min & Photolysis \\
$S_{\max } \mathrm{PH}$ & GEOSCCM & NRL & Max & Heating+Photolysis \\
$S_{\min } \mathrm{PH}$ & GEOSCCM & NRL & Min & Heating+Photolysis \\
$S_{\max } \mathrm{PH}(\mathrm{SORCE})$ & GEOSCCM & SORCE & Max & Heating+Photolysis \\
$S_{\min } \mathrm{PH}(\mathrm{SORCE})$ & GEOSCCM & SORCE & Min & Heating+Photolysis \\
$2-\mathrm{D} S_{\max } \mathrm{PH}$ & GSFC 2-D & NRL & Max* & Heating+Photolysis \\
$2-\mathrm{D} S_{\min } \mathrm{PH}$ & GSFC 2-D & NRL & Min & Heating+Photolysis \\
$2-\mathrm{D} S_{\max } \mathrm{PH}(\mathrm{SORCE})$ & GSFC 2-D & SORCE & Max* & Heating+Photolysis \\
$2-\mathrm{D} S_{\min } \mathrm{PH}(\mathrm{SORCE})$ & GSFC 2-D & SORCE & Min & Heating+Photolysis \\
\hline * $S_{\max }$ conditions in the GSFC 2-D model were applied alternatively at wavelengths $<242 \mathrm{~nm},>242 \mathrm{~nm}$, and over the entire \\
spectrum $($ see Fig. 9).
\end{tabular}
spectrum (see Fig. 9).

feedbacks during different phases of the solar cycle, particularly in the lower stratosphere, but eight multi-ensemble transient simulations would be too computationally expensive. As discussed below in Sect. 5, the ozone and temperature responses to the solar cycle in the GEOSCCM time slices are largely consistent with transient simulations using other models, so for the purposes of this study, the use of computationally economical time slices is justified.

Each time-slice run was a 30-yr simulation in which greenhouse gases (other than $\mathrm{CO}_{2}$ ) and ozone-depleting substance emissions were fixed at 2005 values by specifying their mixing ratios in the lowest model layer, based on established inventories (World Meteorological Organization, 2003; Eyring et al., 2006). Aerosols, including sulfate surface area, were fixed to 1979 values. In contrast, sea surface temperatures (SSTs) and sea ice distributions were allowed to follow their observed 1979-2008 evolutions, specified in the model using the Hadley Centre Ice and Sea-Surface Temperature dataset (Rayner et al., 2003). For consistency with the climate change signal in SSTs, $\mathrm{CO}_{2}$ was also allowed to increase over the same time period according to the IPCC A1B scenario (IPCC, 2000), with the knowledge that SSTs increase with the atmospheric $\mathrm{CO}_{2}$ burden. No quasi-biennial oscillation (QBO) was included in these simulations, but Austin et al. (2008) found little difference in the results of CCMs with and without QBOs. All the model results shown in this work are in the form of $S_{\max }-S_{\min }$ relative differences, so changing $\mathrm{CO}_{2}$ and SSTs in otherwise timeslice simulations would have only a second-order effect and should not bias the present results. All CCM simulations started in SST/CO 2 month January 1979 from a previously spun-up CCM run using mean solar flux conditions. For all the comparisons shown here, the first five model years have been discarded, which would exclude the period of atmospheric adjustment to $S_{\max } / S_{\min }$ conditions. The response in total ozone indicated that the relaxation time of the model atmosphere was actually of the order of months.

\subsection{GSFC 2-D chemistry-radiation-dynamics coupled model}

We also performed a series of simulations using the Goddard Space Flight Center 2-D coupled chemistry-radiationdynamics model (see Table 1). With its computational efficiency, the GSFC 2-D model is ideal for studying the sensitivity of the atmosphere to multiple perturbations in the input SSI and is better suited for conducting a large number of experiments. Two-dimensional models, including the GSFC 2-D model, have been used extensively in international assessments of the stratosphere (e.g., World Meteorological Organization, 2011), and the GSFC 2-D model has been used previously to study the atmospheric response to both 27-day and 11-yr solar cycle variability (Fleming et al., 1995, 2007).

Because its chemistry, radiation, and dynamics are fully coupled, the GSFC model is essentially a 2-D CCM. The current version of the GSFC 2-D was described by Fleming et al. (2011), who have shown that the model simulations compare very well with stratospheric observations and the GEOS 3-D CCM. For consistency with GEOSCCM simulations presented here, the same input SSI spectra representing $S_{\max }$ and $S_{\min }$ conditions derived from the NRL and SORCE SSI were used. Thirty-year time-slice runs were performed with the 2-D model, and the final year of simulation was analyzed (averaging over more years is not necessary because of the almost negligible interannual variability in the 2-D model, compared with the GEOSCCM). 


\section{Discussion}

\subsection{Solar cycle response through heating and photolysis}

The atmosphere responds to the 11 -yr cycle in solar radiation through direct atmospheric heating and the photolysis of $\mathrm{O}_{2}$ and trace gases, such as ozone. These different manifolds have been examined in a GCM by performing simulations alternatively with the solar cycle in direct radiative heating and with the solar signal in specified ozone variations, respectively (Shibata and Kodera, 2005). The advantage of using a CCM, however, is that secondary feedback mechanisms are coupled. For example, when the solar cycle is included only in heating (e.g., runs $S_{\max } \mathrm{H}$ and $S_{\min } \mathrm{H}$ in Table 1), although the solar cycle in photolysis is intentionally excluded, the ozone loss due to greater direct heating at $S_{\max }$ and its feedbacks are still captured.

The response of the atmosphere through heating and photolysis were examined individually and in combination in the GEOSCCM by including the NRL SSI solar cycle selectively in direct heating and photolysis (and both combined), with the model runs listed in Table 1. All results are reported relative to 100 units of $F_{10.7}$ (the total $F_{10.7}$ variation in a typical solar cycle is about 125 ).

\subsubsection{Ozone}

The solar cycle impact on the ozone profile is considered first. Figure 2 shows profiles of the $S_{\max }-S_{\min }$ ozone relative difference, averaged over $60^{\circ} \mathrm{S}-60^{\circ} \mathrm{N}$, based on $25 \mathrm{yr}$ of time-slice simulation forced by the NRL SSI. In the heating+photolysis simulation, $S_{\max } \mathrm{PH}-S_{\min } \mathrm{PH}$, the magnitude of the solar cycle difference peaks in the upper middle stratosphere near $3 \mathrm{hPa}$ at about $+2.0 \%$ per 100 units of $F_{10.7}$. This is generally consistent with other modeling efforts and observations (e.g., Austin et al., 2008). The magnitude of the secondary, lower stratospheric maximum, below $50 \mathrm{hPa}$, is somewhat smaller and confined to lower altitudes than those simulated by most of the models studied by Austin et al. One possible explanation for the difference is that the simulations considered by Austin et al. were transient simulations, whereas the GEOSCCM simulations shown here are time slices. However, Austin et al. and Marsh et al. (2007) have also found that the size of the lower stratospheric peak from transient solar forcing is sensitive to the time period analyzed due to the aliasing of other periodic or quasi-periodic forcings. See Fig. 4 for the tropical ozone response.

The heating-only case shows a slight negative ozone response above $30 \mathrm{hPa}$, due to increased ozone loss rates at warmer temperatures, with a positive response in the lower stratosphere where dynamics plays a larger role. The photolysis-only simulation captures almost all of the solar cycle effect on ozone. Comparison of the three simulations also reveals that the direct heating and photolysis response mechanisms are roughly linearly separable above $30 \mathrm{hPa}$.

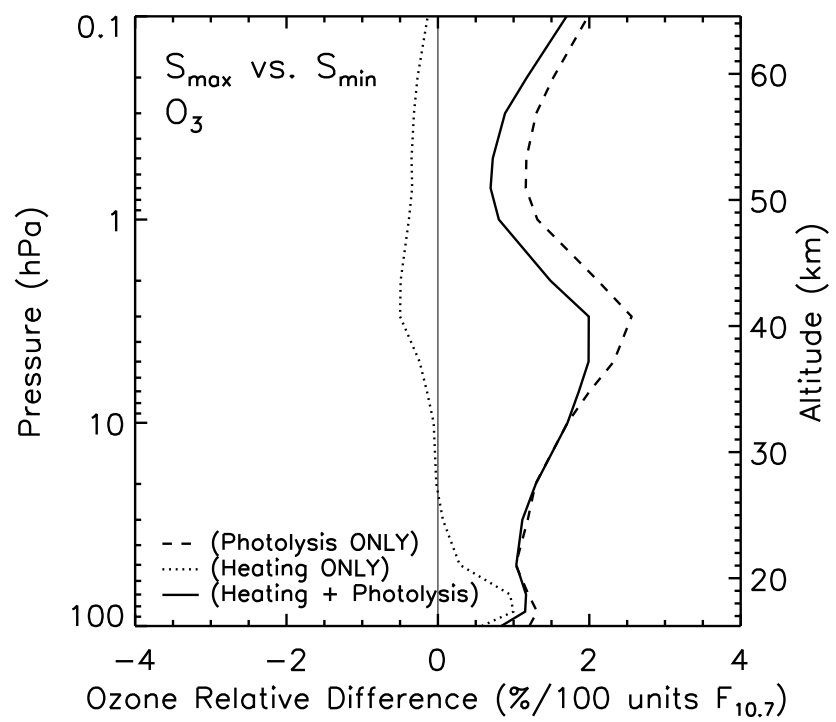

Fig. 2. Ozone response to the $11-y r$ solar cycle, $S_{\max }-S_{\min }$ (relative \%) per 100 units of $F_{10.7}$, in the stratosphere and lower mesosphere and averaged over $60^{\circ} \mathrm{S}-60^{\circ} \mathrm{N}$ latitude, as modeled by the GEOSCCM using the NRL SSI. Three cases are shown, where the solar cycle has been applied (1) only to direct radiative heating, (2) only to photolysis, and (3) with both effects combined.

The solar cycle in SSI leads to a mean total ozone enhancement of 3 Dobson Units per 100 units of $F_{10.7}$ in the tropics going from $S_{\min }$ to $S_{\max }$ (see Fig. 6). This overall effect is similar to previous modeling efforts (e.g., Austin et al., 2008; Marsh et al., 2007) and the solar cycle term derived from regression analyses of merged ozone data (e.g., Stolarski et al., 2006) and ground-based measurements (e.g., Randel and $\mathrm{Wu}, 2007)$. At polar latitudes, the modeled interannual variability is quite significant, with larger variability in the Northern Hemisphere (not shown). Similar conclusions can be drawn from the total ozone response regarding the relative contributions of direct heating and photolysis and their linear separability (not shown).

Thus, in the case of ozone above the lower stratosphere (which is affected by dynamics), the solar cycle response is caused almost entirely through photolysis, with heating providing only a small, mostly negative effect. This is important in that it suggests that CTMs (e.g., Stolarski et al., 2006) should be sufficient to capture the response in ozone to solar cycle variability - chemistry feedback to the radiation and dynamics is of secondary importance.

\subsubsection{Temperature}

The corresponding plot for the solar cycle impact on temperature is shown in Fig. 3. The maximum effect occurs near the stratopause at about $0.6 \mathrm{~K}$ per 100 units of $F_{10.7}$, at $60^{\circ} \mathrm{S}-$ $60^{\circ} \mathrm{N}$. In contrast to ozone's response to the solar cycle, however, both direct heating and photolysis contribute positively 


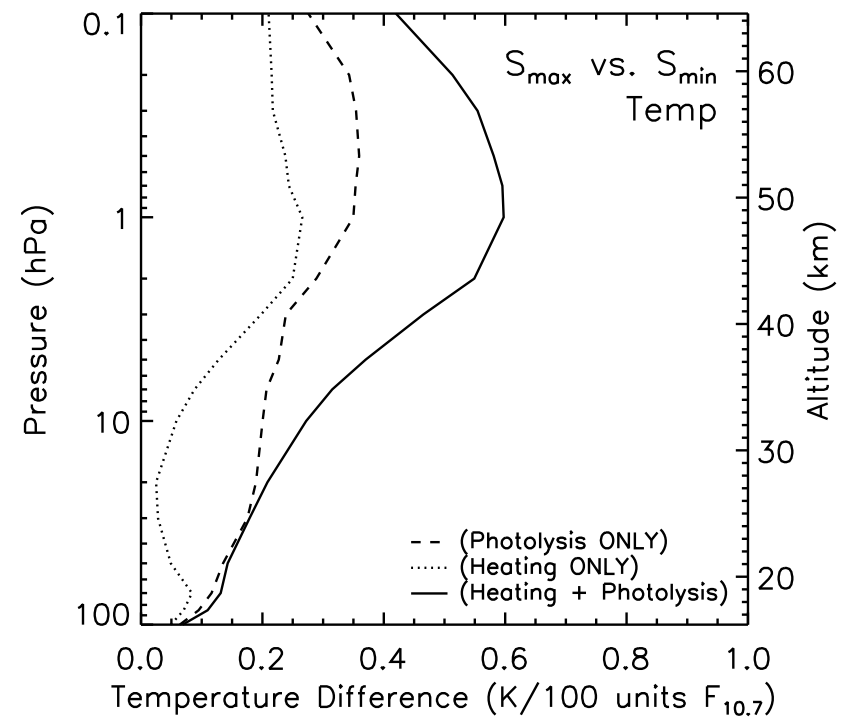

Fig. 3. Same as Fig. 2, but for the temperature response to the solar cycle.

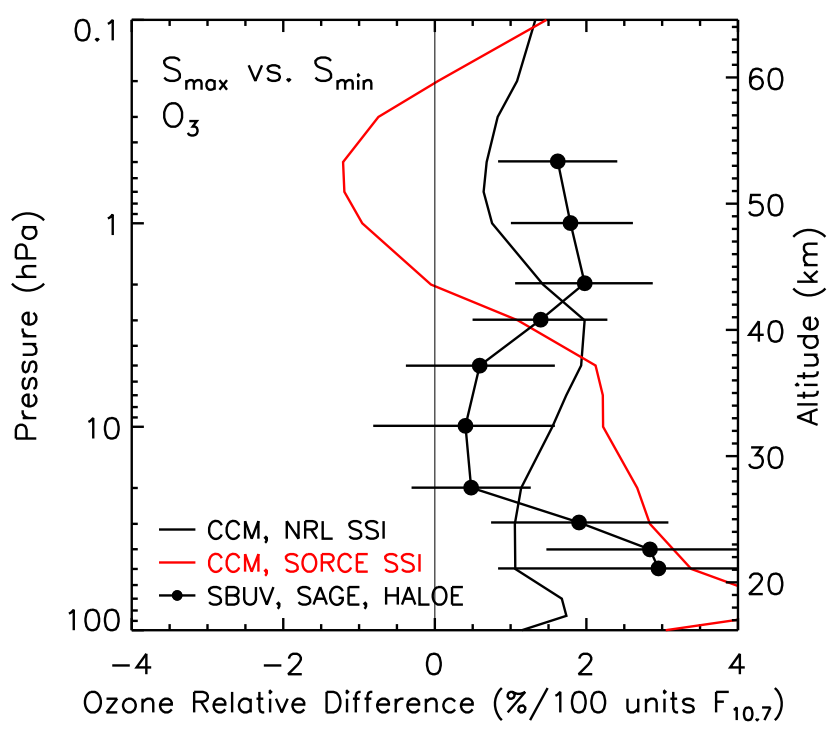

Fig. 4. Simulated ozone solar cycle response in the GEOSCCM using both NRL and SORCE SSI, averaged over $25^{\circ} \mathrm{S}-25^{\circ} \mathrm{N}$ latitude. Also shown is the solar cycle variation in ozone deduced from SBUV, SAGE, and HALOE satellite measurements (Austin et al. (2008), Fig. 4; see also Soukharev and Hood, 2006).

to warmer temperatures at solar maximum. In fact, the additional ozone produced via $\mathrm{O}_{2}$ photolysis with greater UV flux at $S_{\max }$ leads to a larger temperature response than the solar cycle in direct heating itself. Further, the two mechanisms are close to linearly additive throughout most of the middle and upper stratosphere and lower mesosphere.

The finding that direct heating and photolysis both make significant contributions to the increased stratospheric temperatures associated with solar maximum conditions implies that GCMs do not adequately represent the atmospheric response to SSI solar cycle variability. Without including the solar cycle in photolysis, a GCM would substantially underestimate the temperature response.

\subsection{Response to the SORCE SSI solar cycle}

Using the $S_{\max }, S_{\min }$ SSI cases described in Sect. 3.3, we next compare the atmospheric responses to the NRL and SORCE SSI (see SSI spectra in Fig. 1). The results for ozone are shown in Figs. 4 and 5. The response using the NRL SSI shown in Fig. 4 is the same as the heating+photolysis case in Fig. 2. The modeled response shown in Fig. 5 is statistically significant ( $95 \%$ confidence level) throughout most of the plotted range, as indicated. The ozone response to the NRL SSI is positive at all altitudes, up through the middle mesosphere. The response using the SORCE SSI is very different in comparison. Although the ozone response in most of the stratosphere going from $S_{\min }$ to $S_{\max }$ is positive, or in phase with the solar cycle in TSI, above about $2 \mathrm{hPa}$ the response is actually negative (up to $0.2 \mathrm{hPa}$ ). This modeled response is largely consistent with previously published results (e.g., Haigh et al., 2010; Merkel et al., 2011) and with the GSFC 2-D model (see Fig. 9).

Recent analyses of ozone trends over the SORCE time period, representing part of solar cycle 23 , have been used to infer an out-of-phase ozone response in the upper stratosphere/lower mesosphere from Aura/MLS (Haigh et al., 2010) and TIMED/SABER (Merkel et al., 2011) measurements. It must be stressed, however, that extracting statistically significant ozone trends from partial solar cycles is extremely challenging (Garcia, 2010). The ozone signal is small, and there are other competing variations on various time scales, such as those caused by the quasibiennial oscillation, the El Niño Southern Oscillation, volcanic eruptions, declining concentrations of ozone-depleting substances, and climate change (e.g., Stolarski et al., 2006).

Longer satellite ozone records are available and have been studied as well, in detail. The solar cycle in ozone inferred from three solar cycle's worth of satellite observations by the Solar Backscatter Ultraviolet Instrument (SBUV), the Stratospheric Aerosol and Gas Experiment (SAGE), and HALOE, also shown in Fig. 4, lead to a combined ozone response that is positive everywhere in this altitude range (Austin et al., 2008; Soukharev and Hood, 2006), similar to the NRL SSIbased simulation. These longer-term studies, however, do not include the declining phase of solar cycle 23 , and thus a unique solar cycle variation during the SORCE mission (e.g., 2004-present) cannot be ruled out. Another complication in these long satellite records is that occultation instruments, such as SAGE and HALOE, make their observations near the terminator, at a time of rapid diurnal variation in mesospheric ozone (e.g., Merkel et al., 2011).

The longest, perhaps least ambiguous record of the ozone response to the solar cycle is that of total column ozone, 

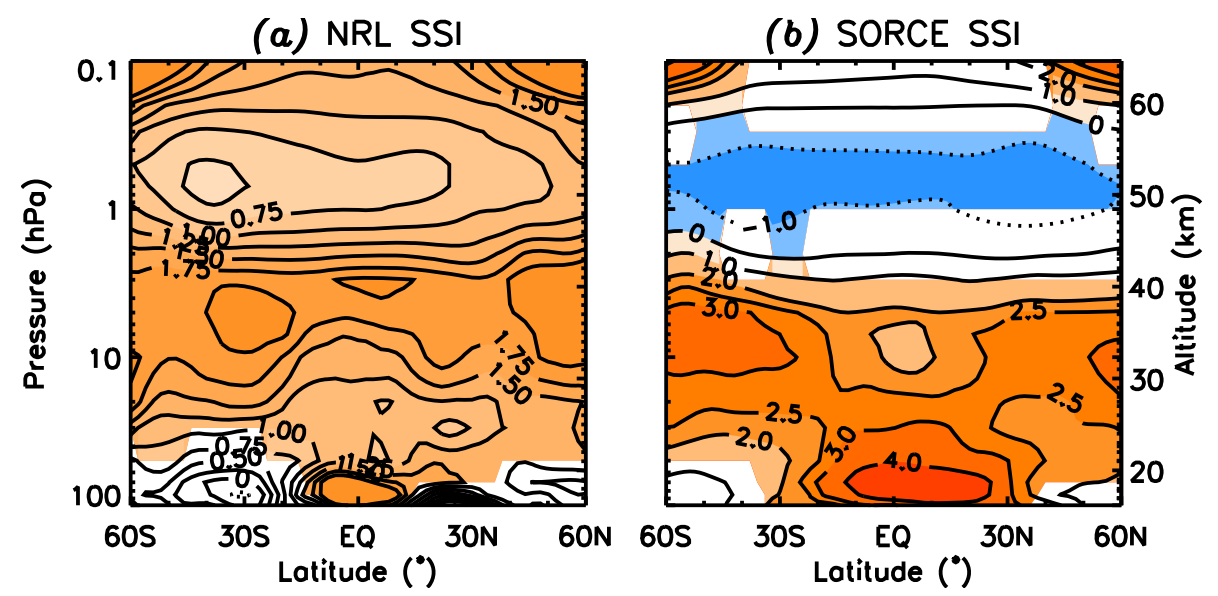

Fig. 5. Simulated ozone solar cycle response in the GEOSCCM, similar to Fig. 4 but in altitude-latitude cross section, using (a) NRL and (b) SORCE SSI. The colored (non-white) portions of the plots indicate regions where the ozone response is statistically significant at the $95 \%$ confidence level.

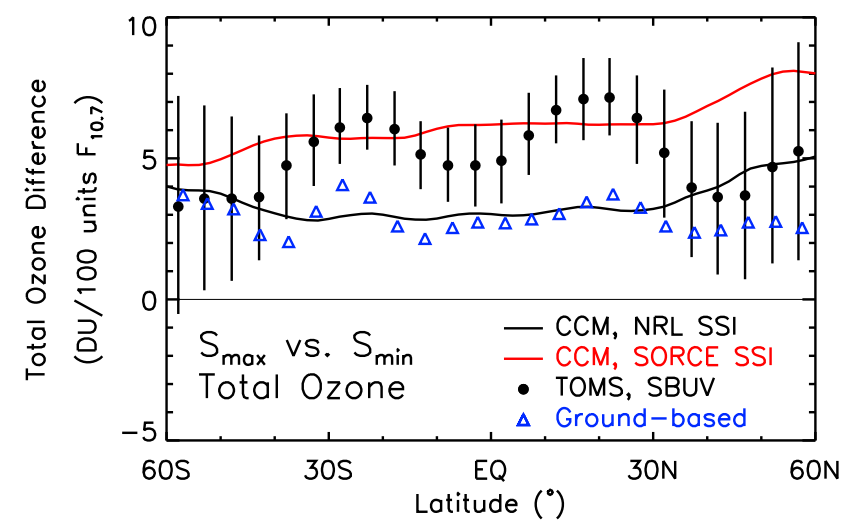

Fig. 6. Total ozone response to the 11-yr solar cycle, as modeled by the GEOSCCM and inferred from observations by regression analyses of the TOMS, SBUV merged total ozone dataset (Stolarski et al., 2006, Fig. 6) and ground-based observations (Randel and Wu, 2007, Fig. 12).

as shown in Fig. 6. The solar cycle response derived from ground-based observations (Randel and $\mathrm{Wu}, 2007$ ) agrees well with the GEOSCCM using NRL SSI. The inferred solar cycle from merged Total Ozone Mapping Spectrometer (TOMS) and SBUV total ozone data (Stolarski et al., 2006; Randel and $\mathrm{Wu}, 2007)$ is larger than that from ground-based measurements (roughly double in the tropics) but is similar to the modeled response based on SORCE SSI. Because most of the total ozone column is in the lower stratosphere, however, note the limitations of time-slice simulations discussed above (Sect. 4.1) regarding the details of lower stratospheric ozone. The total ozone maxima near $20^{\circ} \mathrm{N}$ and $20^{\circ} \mathrm{S}$ latitude in the observations in Fig. 6 are an indication of dynamical processes in the lower stratosphere (see also Hood and Soukharev, 2012) that are not captured in the time-slice simulations. In any event, large statistical uncertainties make it

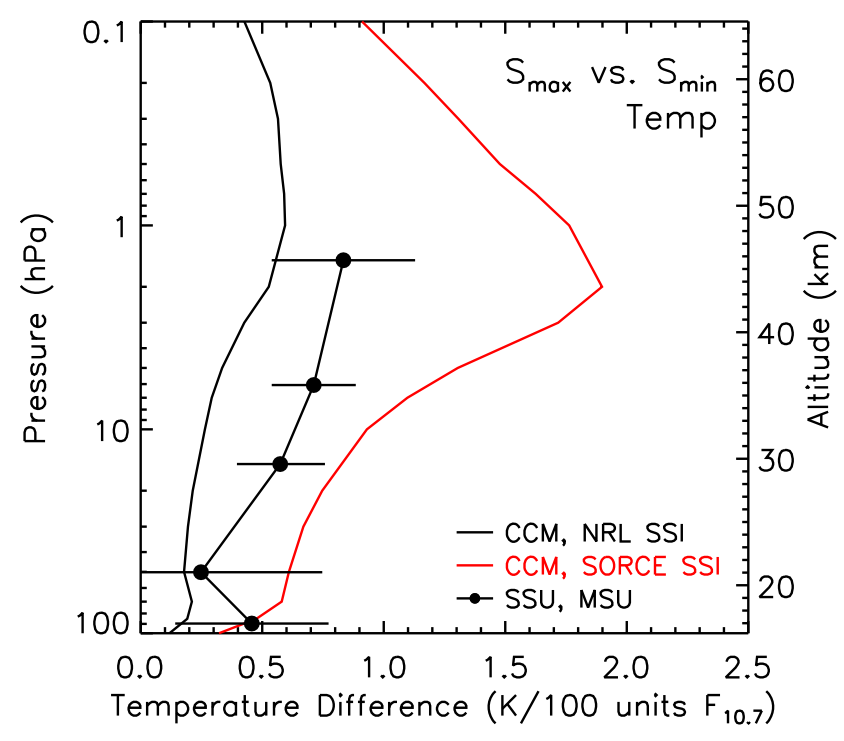

Fig. 7. Same as Fig. 4, but for temperature. SSU = Stratospheric Sounding Unit; MSU = Microwave Sounding Unit; data from (Austin et al., 2008, Fig. 12).

difficult to distinguish between these four representations of the solar cycle in total ozone.

The modeled solar cycle response in temperature is shown in Figs. 7 and 8. In the NRL SSI case, the temperature response to the solar cycle is roughly $0.6 \mathrm{~K}$ per 100 units of $F_{10.7}$ in the tropics, peaking near the stratopause. Note that this response in the GEOSCCM, which includes the effect of feedback from net solar cycle ozone production via $\mathrm{O}_{2}$ photolysis (and thus additional heating) is significantly larger than that predicted with a GCM without coupled chemistry (e.g., Cahalan et al., 2010). The modeled response using the SORCE SSI is much larger still, almost $2 \mathrm{~K}$ per 100 units of $F_{10.7}$, peaking near $2 \mathrm{hPa}$. The fact that the response peaks 

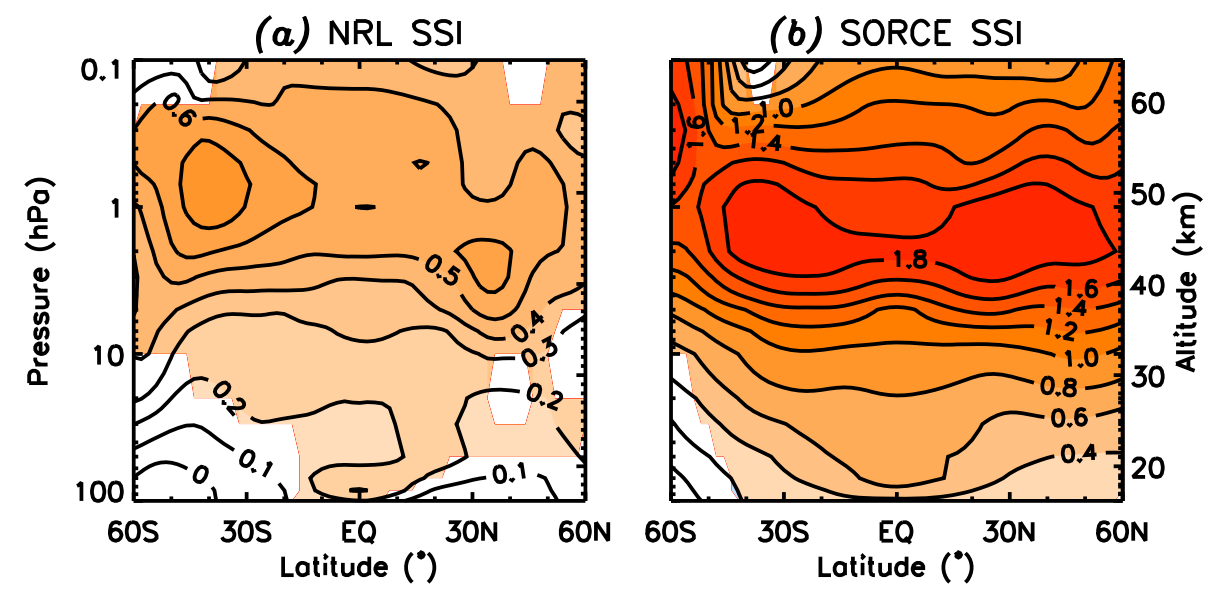

Fig. 8. Same as Fig. 5 but for temperature.
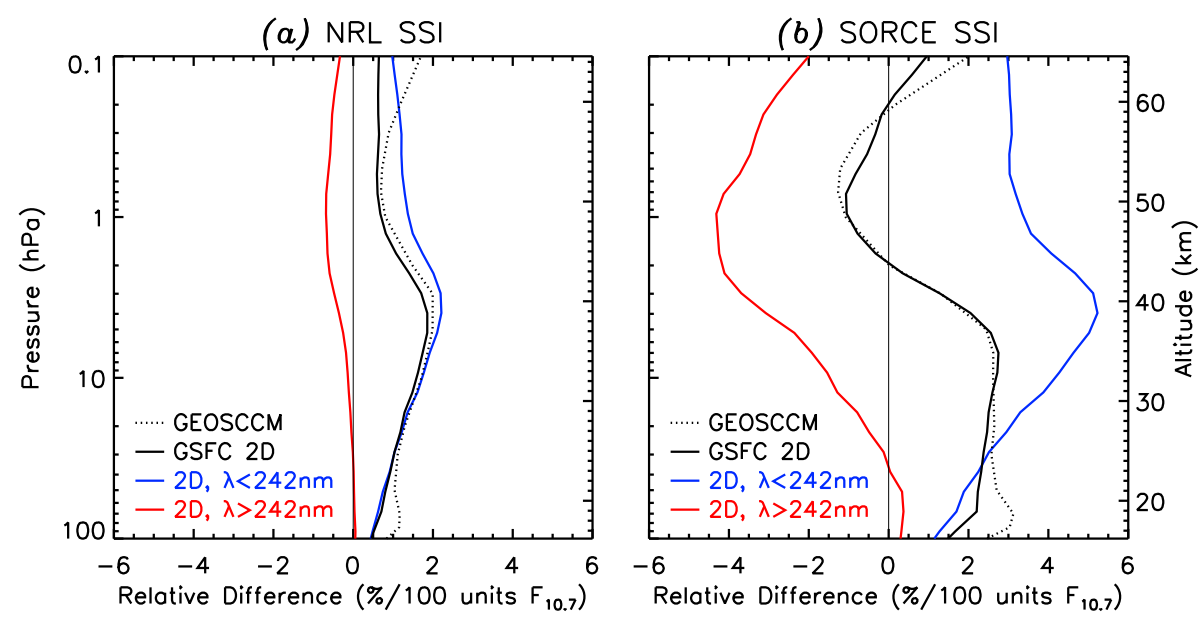

Fig. 9. Simulated ozone response to the solar cycle at wavelengths less and greater than $242 \mathrm{~nm}$ using both (a) NRL and (b) SORCE SSI in the GSFC 2-D model, along with the total responses, averaged over $60^{\circ} \mathrm{S}-60^{\circ} \mathrm{N}$ latitude. Also shown are the analogous GEOSCCM total responses (corresponding to the simulations in Fig. 4 but averaged over $60^{\circ} \mathrm{S}-60^{\circ} \mathrm{N}$ ) for comparison.

at a lower altitude is not surprising, considering the relative ozone loss in the lower mesosphere and the large SORCE SSI variation in the ozone Huggins bands wavelength region (300-360 nm), which penetrates lower into the atmosphere. At its peak, the SORCE SSI case is over twice as large as the solar cycle temperature response inferred from either HALOE (Remsberg, 2008) or microwave temperature sounding (Fig. 7; Austin et al., 2008).

\subsection{Decomposition of the ozone response as a function of wavelength}

The response of the atmosphere to the 11-yr solar cycle is sensitive to the spectral characteristics of the SSI solar cycle variation. As discussed in Sect. 2, increasing UV radiation from $S_{\min }$ to $S_{\max }$ increases both $\mathrm{O}_{2}$ photolysis, leading directly to ozone production, and ozone photolysis to form atomic oxygen, which leads to catalytic ozone loss. Al- though ozone photolysis occurs between roughly 200 and $340 \mathrm{~nm}$, the ozone balance is dominated by $\mathrm{O}_{2}$ photolysis below $242 \mathrm{~nm}$. At wavelengths longer than this $\mathrm{O}_{2}$ photolysis threshold, the situation is driven by ozone photolysis and catalytic loss. This means that the net ozone production/loss in the photochemically controlled upper stratosphere/lower mesosphere is determined by the relative contributions of these two wavelength ranges. Coincidentally, the 242-nm threshold is close to the recommended minimum wavelength for use of the SIM SSI data (see SSI spectra in Fig. 1), so the net ozone response to the solar cycle results from the relative size of the solar cycle inferred from the SOLSTICE and SIM instruments of the SORCE mission.

To study the details of the contributions of the SSI variations on either side of the 242-nm threshold to the ozone response, we used the GSFC 2-D model, described in Sect. 4.2. The 2-D model, with fully coupled chemistry-radiationdynamics, is essentially a 2-D CCM. Although the 2-D 
model may not capture all the details of ozone transport in the lower stratosphere, it is more than adequate for the photochemical problem posed here. Figure 9 shows the ozone response to the solar cycle as described by the NRL and SORCE SSI and the excellent agreement between the 2-D model and the GEOSCCM. This figure also shows 2-D model simulations where the solar cycle in SSI is applied alternatively at wavelengths less and greater than $242 \mathrm{~nm}$. The ozone production-dominant short-wavelength region of the solar cycle leads to enhanced ozone throughout the stratosphere and lower mesosphere, whereas the solar cycle at longer wavelengths leads to ozone loss at virtually all altitudes.

The ozone responses at wavelengths less and greater than $242 \mathrm{~nm}$ are qualitatively similar for both the NRL and SORCE SSI. The quantitative difference in the total responses between the two SSI specifications results from the balance of the two wavelength regimes. The magnitude of the solar cycle in the SOLSTICE part of the SSI spectrum $(\lambda<242 \mathrm{~nm})$ is greater than the NRL SSI, leading to a peak ozone production more than a factor of 2 larger. The magnitude in the SIM region $(\lambda>242 \mathrm{~nm})$, however, is greater by roughly a factor of 6 at its peak. The ozone response to the solar cycle in both parts of the spectrum combined is almost exactly equivalent to the linear combination of the responses in the individual wavelength ranges (not shown explicitly). And it is the balance of these ozone production and loss regimes that results in the very different total responses in the model when forced with the NRL and SORCE SSI, including the altitude at which the SORCE ozone response goes from in-phase (with respect to the solar cycle in TSI) in the lower and middle stratosphere to out-of-phase near and above the stratopause.

\section{Conclusions}

Model simulations using the GEOSCCM and GSFC 2-D coupled model have been used to further clarify how the atmosphere responds to the SSI solar cycle. Using the GEOSCCM to explore the effects of SSI variations on direct atmospheric heating and photolysis both separately and when combined, we have quantified their relative contributions in relaying solar cycle variations to stratospheric ozone and temperature. We have shown how the response of ozone to the solar cycle is almost entirely due to the solar cycle in photolysis, whereas the solar cycle in both photolysis and direct atmospheric heating are important for the temperature response. This means that CTMs should simulate the ozone response well, while GCMs without coupled chemistry will underestimate the temperature response significantly. Also, the responses through photolysis and heating are linearly additive to first order for both ozone and temperature.
Simulations presented here with the GEOSCCM and GSFC 2-D model confirm recent simulations based on both the NRL and SORCE SSI (Haigh et al., 2010; Merkel et al., 2011). The NRL SSI produces an ozone response that is in phase with the solar cycle in TSI throughout the stratosphere and lower mesosphere, whereas the SORCE SSI produces an out-of-phase response in the uppermost stratosphere and lower mesosphere. Although this model result based on the SORCE SSI is more consistent with the ozone solar cycle inferred from recent satellite observations (Haigh et al., 2010; Merkel et al., 2011), caution should be exercised when drawing conclusions. Using climate or chemistry-climate model output in comparison with a solar cycle inferred from a short data record is probably not the best way to validate the solar cycle inferred from SSI measurements. Even the most comprehensive models are subject to numerous simplifications. In addition, inferring solar cycle variations from part of a solar cycle is challenging (Garcia, 2010). A more convincing approach is to make comparisons with the SSI observations themselves, such as has been done by Morrill et al. (2012) and DeLand and Cebula (2012). Lean and DeLand (2012) in fact argue that the unexpected solar cycle variations inferred from the SORCE SIM instrument are the result of undetected instrument sensitivity drifts and therefore caution against using the SIM-derived 11-yr solar cycle in climate simulations until further validation and uncertainty estimation are available. Ultimately, continued observation of the SSI by SORCE and subsequent missions will likely be necessary to definitively resolve the NRL-SORCE discrepancies. Further, it is possible that interpretation of the SORCE measurements will change as more of solar cycle 24 is observed.

We have also shown using 2-D model simulations that the net ozone response in the middle atmosphere results from the SSI-determined balance of ozone production at wavelengths less than $242 \mathrm{~nm}$ and ozone destruction at longer wavelengths. These linearly separable wavelength regimes roughly correspond to those of the SOLSTICE and SIM instruments on SORCE, respectively, meaning the relative sizes of the UV SSI solar cycle variations inferred from these two instruments determine the magnitude and phase (with respect to the solar cycle in total solar irradiance) of the ozone response. An analysis of the atmospheric response at finer wavelength resolution and its linearity could allow for a better prediction of the atmospheric response to arbitrary SSI variations.

Acknowledgements. We thank J. W. Harder (University of Colorado/Laboratory for Atmospheric and Space Physics) for providing the SORCE/SIM SSI time series data, and we similarly thank J. Lean (Naval Research Laboratory) for the NRL SSI reconstruction. We appreciate the constructive comments on this paper provided by L. L. Hood (University of Arizona) and another, anonymous referee. The $10.7-\mathrm{cm}$ radio flux data were obtained from the NOAA National Geophysical Data Center (http://ngdc.noaa.gov). Resources supporting this work were 
provided by the NASA High-End Computing (HEC) Program through the NASA Advanced Supercomputing (NAS) Division at the NASA/Ames Research Center. This work was supported by NASA under grants NNX09AQ74G, issued through the NASA/Goddard Space Flight Center, and NNX11AR19G, through the Living With a Star Targeted Research and Technology program.

Edited by: M. Dameris

\section{References}

Austin, J., Tourpali, K., Rozanov, E., Akiyoshi, H., Bekki, S., Bodeker, G., Brühl, C., Butchart, N., Chipperfield, M., Deushi, M., Fomichev, V. I., Giorgetta, M. A., Gray, L., Kodera, K., Lott, F., Manzini, E., Marsh, D., Matthes, K., Nagashima, T., Shibata, K., Stolarski, R. S., Struthers, H., and Tian, W.: Coupled Chemistry Climate Model Simulations of the Solar Cycle in Ozone and Temperature, J. Geophys. Res., 113, D11306, doi:10.1029/2007JD009391, 2008.

Brasseur, G. and Solomon, S.: Aeronomy of the Middle Atmosphere, D. Reidel, second edn., 1986.

Brueckner, G. E., Edlow, K. L., Floyd, L. E., Lean, J., and Vanhoosier, M. E.: The Solar Ultraviolet Spectral Irradiance Monitor (SUSIM) experiment onboard the Upper Atmosphere Research Satellite (UARS), J. Geophys. Res., 98, 10695-10711, 1993.

Cahalan, R. F., Wen, G., Harder, J. W., and Pilewskie, P.: Temperature Response to Spectral Solar Variability on Decadal Time Scales, Geophys. Res. Lett., 37, L07705, doi:10.1029/2009GL041898, 2010.

DeLand, M. T. and Cebula, R. P.: Solar UV Variations During the Decline of Cycle 23, J. Atmos. Sol-Terr. Phys., 77, 225-234, doi:10.1016/j.jastp.2012.01.007, 2012.

Douglass, A. R., Weaver, C. J., Rood, R. B., and Coy, L.: A Three-Dimensional Simulation of the Ozone Annual Cycle Using Winds From a Data Assimilation System, J. Geophys. Res., 101, 1463-1474, 1996.

Eyring, V., Butchart, N., Waugh, D. W., Akiyoshi, H., Austin, J., Bekki, S., Bodeker, G. E., Boville, B. A., Brühl, C., Chipperfield, M. P., Cordero, E., Dameris, M., Deushi, M., Fioletov, V. E., Frith, S. M., Garcia, R. R., Gettelman, A., Giorgetta, M. A., Grewe, V., Jourdain, L., Kinnison, D. E., Mancini, E., Manzini, E., Marchand, M., Marsh, D. R., Nagashima, T., Newman, P. A., Nielsen, J. E., Pawson, S., Pitari, G., Plummer, D. A., Rozanov, E., Schraner, M., Shepherd, T. G., Shibata, K., Stolarski, R. S., Struthers, H., Tian, W., and Yoshiki, M.: Assessment of Temperature, Trace Species, and Ozone in Chemistry-Climate Model Simulations of the Recent Past, J. Geophys. Res., 111, D22308, doi:10.1029/2006JD007327, 2006.

Fleming, E. L., Chandra, S., Jackman, C. H., Considine, D. B., and Douglass, A. R.: The Middle Atmospheric Response to Short and Long Term Solar UV Variations: Analysis of Observations and 2D Model Results, J. Atmos. Terr. Phys., 57, 333-365, 1995.

Fleming, E. L., Jackman, C. H., Weisenstein, D. K., and Ko, M. K. W.: The Impact of Interannual Variability on Multidecadal Total Ozone Simulations, J. Geophys. Res., 112, D10310, doi:10.1029/2006JD007953, 2007.

Fleming, E. L., Jackman, C. H., Stolarski, R. S., and Douglass, A. R.: A model study of the impact of source gas changes on the stratosphere for 1850-2100, Atmos. Chem. Phys., 11, 85158541, doi:10.5194/acp-11-8515-2011, 2011.

Fröhlich, C. and Lean, J.: The Sun's Total Irradiance: Cycles, Trends and Related Climate Change Uncertainties Since 1976, Geophys. Res. Lett., 25, 4377-4380, 1998.

Fröhlich, C. and Lean, J.: Solar Radiative Output and its Variability: Evidence and Mechanisms, Astron. Astrophys. Rev., 12, 273320, doi:10.1007/s00159-004-0024-1, 2004.

Garcia, R. R.: Solar Surprise?, Nature, 467, 668-669, doi:10.1038/467668a, 2010.

Garcia, R. R., Solomon, S., Roble, R. G., and Rusch, D. W.: A Numerical Response of the Middle Atmosphere to the 11-Year Solar Cycle, Planet. Space Sci., 32, 411-423, 1984.

Gray, L. J., Beer, J., Geller, M., Haigh, J. D., Lockwood, M., Matthes, K., Cubasch, U., Fleitmann, D., Hood, G. H., Luterbacher, J., Meehl, G. A., Shindell, D., van Geel, B., and White, W.: Solar Influences on Climate, Rev. Geophys., 48, RG4001, doi:10.1029/2009RG000282, 2010.

Haigh, J. D.: The Impact of Solar Variability on Climate, Science, 272, 981-984, 1996.

Haigh, J. D., Winning, A. R., Toumi, R., and Harder, J. W.: An Influence of Solar Spectral Variations on Radiative Forcing of Climate, Nature, 467, 696-699, doi:10.1038/nature09426, 2010.

Harder, J. W., Fontenla, J. M., Pilewskie, P., Richard, E. C., and Woods, T. N.: Trends in Solar Spectral Irradiance Variability in the Visible and Infrared, Geophys. Res. Lett., 36, L07801, doi:10.1029/2008GL036797, 2009.

Hood, L. L. and Soukharev, B. E.: The Lower-Stratospheric Response to 11-Yr Solar Forcing: Coupling to the TroposphereOcean Response, J. Atmos. Sci., 69, 1841-1864, 2012.

Huang, T. Y. W. and Brasseur, G. P.: Effect of Long-Term Solar Variability in a Two-Dimensional Interactive Model of the Middle Atmosphere, J. Geophys. Res., 98, 20413-20427, 1993.

Ineson, S., Scaife, A. A., Knight, J. R., Manners, J. C., Dunstone, N. J., Gray, L. J., and Haigh, J. D.: Solar Forcing of Winter Climate Variability in the Northern Hemisphere, Nature Geosci., 4, 753-757, doi:10.1038/ngeo1282, 2011.

IPCC: Special Report on Emission Scenarios. A Special Report of Working Group III of the Intergovernmental Panel on Climate Change, Cambridge University Press, New York, USA, 2000.

IPCC: Climate Change 2007: The Physical Science Basis. Contribution of Working Group I to the Fourth Assessment Report of the Intergovernmental Panel on Climate Change, Cambridge University Press, Cambridge, UK, 2007.

Kopp, G. and Lean, J. L.: A New, Lower Value of Total Solar Irradiance: Evidence and Climate Significance, Geophys. Res. Lett., 38, L01706, doi:10.1029/2010GL045777, 2011.

Kopp, G., Lawrence, G., and Rottman, G.: The Total Irradiance Monitor (TIM): Science Results, Solar Phys., 230, 129-140, 2005.

Lean, J.: Evolution of the Sun's Spectral Irradiance Since the Maunder Minimum, Geophys. Res. Lett., 27, 2425-2428, 2000.

Lean, J. L. and DeLand, M. T.: How Does the Sun's Spectrum Vary?, J. Climate, 25, 2555-2560, 2012.

Marsh, D. R., Garcia, R. R., Kinnison, D. E., Boville, B. A., Sassi, F., Solomon, S. C., and Matthes, K.: Modeling the Whole Atmosphere Response to Solar Cycle Changes in Radiative and Geomagnetic Forcing, J. Geophys. Res., 112, D23306, doi:10.1029/2006JD008306, 2007. 
Matthes, K.: Solar Cycle and Climate Predictions, Nature Geosci., 4, 735-736, 2011.

McClintock, W. E., Rottman, G. J., and Woods, T. N.: Solar Stellar Irradiance Comparison Experiment II (SOLSTICE II): Instrument Concept and Design, Solar Phys., 230, 225-258, 2005.

Merkel, A. W., Harder, J. W., Marsh, D. R., Smith, A. K., Fontenla, J. M., and Woods, T. N.: The Impact of Solar Spectral Irradiance Variability on Middle Atmospheric Ozone, Geophys. Res. Lett., 38, L13802, doi:10.1029/2011GL047561, 2011.

Morrill, J. S., Floyd, L., and McMullin, D.: Comparison of Solar UV Spectral Irradiance from SUSIM and SORCE, Solar Phys., in preparation, 2012.

Pawson, S., Stolarski, R. S., Douglass, A. R., Newman, P. A., Nielsen, J. E., Frith, S. M., and Gupta, M. L.: Goddard Earth Observing System Chemistry-Climate Model Simulations of Stratospheric Ozone-Temperature Coupling Between 1950 and 2005, J. Geophys. Res., 113, D12103, doi:10.1029/2007JD009511, 2008.

Randel, W. J. and Wu, F.: A Stratospheric Ozone Profile Data Set for 1979-2005: Variability, Trends, and Comparisons With Column Ozone Data, J. Geophys. Res., 112, D06313, doi:10.1029/2006JD007339, 2007.

Rayner, N. A., Parker, D. E., Horton, E. B., Folland, C. K., Alexander, L. V., Rowell, D. P., Kent, E. C., and Kaplan, A.: Global Analyses of Sea Surface Temperature, Sea Ice, and Night Marine Air Temperature Since the Late Nineteenth Century, J. Geophys. Res., 108, 4407, doi:10.1029/2002JD002670, 2003.

Remsberg, E. E.: On the Response of Halogen Occultation Experiment (HALOE) Stratospheric Ozone and Temperature to the 11-Year Solar Cycle Forcing, J. Geophys. Res., 113, D22304, doi:10.1029/2008JD010189, 2008.

Rienecker, M. M., Suarez, M. J., Todling, R., Bacmeister, J., Takacs, L., Liu, H.-C., Gu, W., Sienkiewicz, M., Koster, R. D., Gelaro, R., Stajner, I., and Nielsen, J. E.: The GEOS-5 Data Assimilation System - Documentation of Versions 5.0.1, 5.1.0, and 5.2.0, Tech. Rep. NASA/TM-2008-104606, NASA/Goddard Space Flight Center, Greenbelt, Md., 2008.

Rind, D.: The Sun's Role in Climate Variations, Science, 296, 673677, 2002.

Rind, D., Shindell, D., Perlwitz, J., Lerner, J., Lonegran, P., Lean, J., and McClinden, C.: The Relative Importance of Solar and Anthropogenic Forcing of Climate Change between the Maunder Minimum and the Present, J. Climate, 17, 906-929, 2004.
Rind, D., Lean, J., Lerner, J., Lonergan, P., and Leboissitier, A.: Exploring the Stratospheric/Tropospheric Response to Solar Forcing, J. Geophys. Res., 113, D24103, doi:10.1029/2008JD010114, 2008.

Rottman, G.: The SORCE Mission, Solar Phys., 230, 7-25, 2005.

Rottman, G. J., Woods, T. N., and Sparn, T. P.: SOLar STellar Irradiance Comparison Experiment: Instrument Design and Operation, J. Geophys. Res., 98, 10667-10678, 1993.

Rottman, G., Harder, J., Fontenla, J., Woods, T., White, O. R., and Lawrence, G. M.: The Spectral Irradiance Monitor (SIM): Early Observations, Solar Phys., 230, 205-224, 2005.

Shibata, K. and Kodera, K.: Simulation of Radiative and Dynamical Responses of the Middle Atmosphere to the 11Year Solar Cycle, J. Atmos. Sol-Terr. Phys., 67, 125-143, doi:10.1016/j.jastp.2004.07.022, 2005.

Shindell, D., Rind, D., Balachandran, N., Lean, J., and Lonergan, P.: Solar Cycle Variability, Ozone, and Climate, Science, 284, 305-308, 1999.

Shindell, D., Schmidt, G. A., Mann, M. E., Rind, D., and Waple, A.: Solar Forcing of Regional Climate Change During the Maunder Minimum, Science, 294, 2149-2152, 2001.

Soukharev, B. E. and Hood, L. L.: Solar Cycle Variation of Stratospheric Ozone: Multiple Regression Analysis of Long-Term Satellite Data Sets and Comparisons with Models, J. Geophys. Res., 111, D20314, doi:10.1029/2006JD007107, 2006.

Stolarski, R. S., Douglass, A. R., Steenrod, S., and Pawson, S.: Trends in Stratospheric Ozone: Lessons Learned from a 3D Chemical Transport Model, J. Atmos. Sci., 63, 1028-1041, 2006.

World Meteorological Organization: Scientific Assessment of Ozone Depletion: 2002, Rep. 47, Global Ozone Research and Monitoring Project, Geneva, 2003.

World Meteorological Organization: Scientific Assessment of Ozone Depletion: 2010, Rep. 52, Global Ozone Research and Monitoring Project, Geneva, 2011.

Zhong, W., Osprey, S. M., Gray, L. J., and Haigh, J. D.: Influence of the Prescribed Solar Spectrum on Calculations of Atmospheric Temperature, Geophys. Res. Lett., 35, L22813, doi:10.1029/2008GL035993, 2008. 